\title{
BETON NON-PASIR DENGAN AGREGAT CANGKANG KELAPA SAWIT
}

\author{
Yulius Rief Alkhaly \\ M. Nazar \\ Jurusan Teknik Sipil, Fakultas Teknik, Universitas Malikussaleh \\ email:yr.alkhaly@gmail.com
}

\begin{abstract}
Abstrak
Penelitian ini dimaksudkan untuk memanfaatkan cangkang kelapa sawit sebagai alternatif agregat kasar pada beton non-pasir. Cangkang kelapa sawit mempunyai bobot yang ringan dan kulit yang keras sehingga berpotensi sebagai agregat beton ringan. Beton non-pasir adalah beton ringan yang didapat dengan menghilangkan agregat halus campuran beton normal. Cangkang kelapa sawit yang digunakan berasal dari pabrik kelapa sawit Lhoksukon, Aceh Utara. Cangkang kelapa sawit diayak menggunakan saringan $19-9,5 \mathrm{~mm}$. Benda uji dipersiapkan sebanyak 30 buah berbentuk silender $(15 \times 30) \mathrm{cm}$. Faktor air semen yang digunakan adalah 0,45 dengan perbandingan volume untuk 5 variasi benda uji masing-masing $1: 3 ; 1: 6 ; 1$ : $8 ; 1: 10$ dan $1: 12$. Dari hasil pengujian pada umur 28 hari untuk beton nonpasir dengan perbandingan volume semen dan kerikil $1: 3$ didapat kuat tekan sebesar 8,71 MPa, sedangkan untuk beton non-pasir dengan perbandingan volume semen dan cangkang sawit masing-masing $1: 3 ; 1: 6$; dan $1: 8$ didapat kuat tekan 4,64 MPa, 3,62 MPa, dan 3,06 MPa. Selanjutnya, untuk perbandingan volume semen dan cangkang sawit masing-masing $1: 10$ dan 1 : 12 didapat kuat tekan di bawah $3 \mathrm{MPa}$. Hasil tersebut memperlihatkan bahwa beton non-pasir dengan agregat cangkang sawit pada perbandingan 1 : 3, 1:6; dan 1:8; memenuhi kriteria kuat tekan beton non-pasir yaitu antara 2,8 MPa sampai $10 \mathrm{MPa}$. Dengan demikian, beton non-pasir dari agregat cangkang kelapa sawit dapat diaplikasikan sebagai beton ringan non struktural yang ramah lingkungan karena sifatnya yang tembus air
\end{abstract}

Kata kunci: cangkang kelapa sawit, beton non-pasir, kuat tekan

\section{Pendahuluan}

Kelapa sawit merupakan salah satu komoditi utama hasil perkebunan di kabupaten Aceh Utara. Berdasarkan data Biro Pusat Statistik diketahui bahwa jumlah produksi buah kelapa sawit mencapai 165.139 ton pada tahun 2010 (Aceh Utara Dalam Angka 2011). Keseluruhan produksi tersebut diolah menjadi Crued Palm Oil (CPO) sebagai bahan mentah pembuatan minyak goreng dan mentega. Selain CPO, pengolahan buah kelapa sawit juga menghasilkan produk limbah yang berupa tandan kosong dan cangkang kelapa sawit. Dari 1 ton kelapa sawit akan menghasilkan produk limbah cangkang sebanyak 60 - $80 \mathrm{~kg}$.

Melihat jumlah produksi sampingan dari pengolahan CPO yang cukup besar, maka limbah tersebut berpotensi digunakan untuk memproduksi material lain yang lebih bermanfaat. Selain itu, penggunaan kembali bahan sisa olahan akan mengurangi dampak buruk limbah padat terhadap lingkungan. Selama ini, limbah kelapa sawit hanya dimanfaatkan untuk bahan bakar ketel uap pengolah $\mathrm{CPO}$ atau sebagai bahan baku untuk pembuatan obat nyamuk bakar. Penelitian 
Mannan, M. A., Ganapathy, C., 2001 dan Teo, et. al., 2002, memperlihatkan bahwa cangkang kelapa sawit mempunyai suatu potensi yang baik untuk digunakan pada beton ringan. Cangkang kelapa sawit juga sudah terbukti dapat digunakan sebagai agregat kasar pada beton ringan struktural.

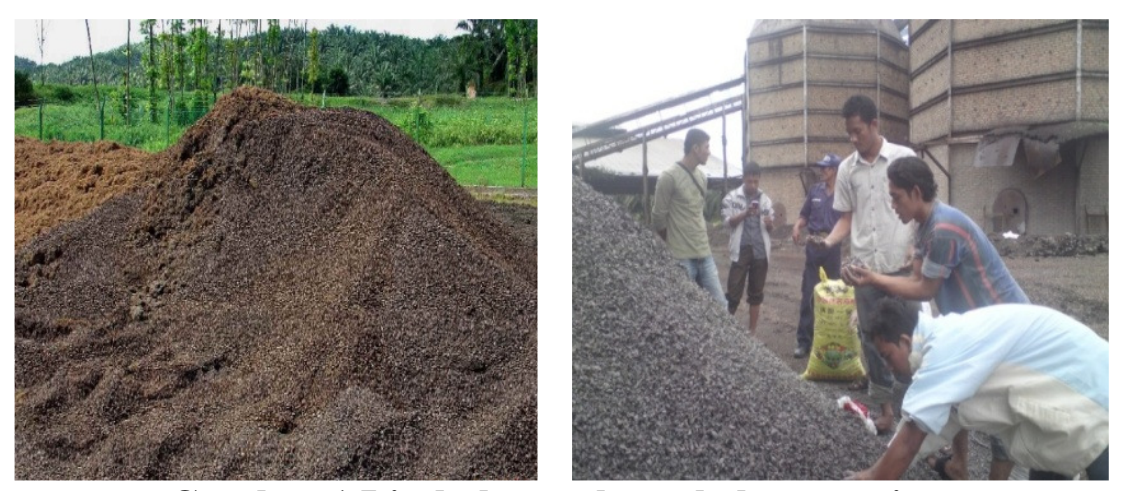

Gambar 1 Limbah cangkang kelapa sawit

SNI 3402-2008 mendefinisikan beton ringan stuktural adalah beton yang memakai agregat ringan atau campuran agregat kasar ringan dan pasir alam sebagai pengganti agregat ringan halus ringan dengan ketentuan tidak boleh melampaui berat maksimum beton $1840 \mathrm{~kg} / \mathrm{m} 3$. Salah satu jenis beton ringan adalah beton non-pasir. Beton ini merupakan beton ringanyang didapat dengan menghilangkan fraksi agregat halus dalam adukan/campuran beton normal.

\section{Dasar Teori}

Beton non-pasir adalah bentuk simpel beton ringan yang didapat dengan menghilangkan fraksi agregat halus dalam adukan/campuran beton normal. Ketiadaan agregat halus di dalam campuran akan dihasilkan suatu sistem distribusi udara yang sama, yang memasuki masa beton. Keuntungan utama dalam penggunaan beton tanpa agregat halus adalah tingginya kemampuan dalam menahan panas, kemampuan dalam menyerap air, kepadatan dan penyusutan rendah (Ferguson, B. K, 2005).

Menurut Neville, A. M., 1995, penggolongan kelas beton ringan berdasarkan berat volume dan kuat tekan dapat dibagi tiga kelompok yaitu:

1. Beton ringan dengan berat volume rendah (Low Density Concretes) untuk non struktur dengan berat jenis antara $300 \mathrm{~kg} / \mathrm{m}^{3}$ sampai $800 \mathrm{~kg} / \mathrm{m}^{3}$ dan kuat tekan antara 0,35 $\mathrm{MPa}$ sampai $7 \mathrm{MPa}$ yang umumnya digunakan untuk dinding pemisah atau dinding isolasi.

2. Beton ringan dengan berat volume menengah (Moderate Strength Concretes) untuk struktur ringan dengan berat jenis $\mathrm{kg} / \mathrm{m}^{3}$ sampai $1350 \mathrm{~kg} / \mathrm{m}^{3}$ dan kuat tekan antara $7 \mathrm{MPa}$ sampai $17 \mathrm{MPa}$ yang umumnya digunakan untuk dinding yang memikul beban.

3. Beton ringan struktur (Struktur Lightweight Concretes) untuk struktur dengan berat volume $1350 \mathrm{~kg} / \mathrm{m}^{3}$ sampai $1900 \mathrm{~kg} / \mathrm{m}^{3}$ dan kuat tekan lebih dari 17 MPa yang dapat digunakan sebagai beton normal. 


\subsection{Campuran beton non-pasir}

Secara tipikal, beton non-pasir dibuat dengan menggunakan faktor air semen (fas) antara 0,35-0,45; dengan kandungan rongga antara agregat sebesar $15 \%$ sampai $25 \%$. Proporsi semen berbanding agregat berkisar antara 1:6 sampai 1:8 dalam perbandingan volume. Beton non-pasir tidak dikatagorikan berdasarkan pada kuat tekannya, tetapi lebih ditekankan pada nilai kerapatan (unit weight). Toleransi berat volume beton non-pasir antara hasil rancangan dan keadannya aktualnya adalah $\pm 80 \mathrm{~kg} / \mathrm{m} 3$. Pengujian slump dan kadar udara untuk beton nonpasir tidaklah berlaku (Anonim, 2004).

\subsection{Sifat beton non-pasir}

\subsubsection{Berat Volume Beton}

Agregat yang digunakan dalam beton non-pasir merupakan agregat dengan ukuran seragam (tunggal). Ukuran agregat tunggal tersebut membentuk kekosongan besar yang saling terkoneksi satu sama lainnya dalam massa beton non-pasir. Struktur porous dari jenis beton non-pasir membentuk berat volume lebih rendah jika dibandingkan dengan beton normal. Berat volume beton nonpasir bervariasi antara 1780 dan $1890 \mathrm{~kg} / \mathrm{m} 3$, yaitu $22 \%$ lebih rendah dari berat volume beton normal (Abadjieva, T., Sephiri, P., 2000).

\subsubsection{Kuat Tekan}

Kekuatan tekan dari beton non-pasir dapat ditentukan setelah umur beton mencapai 7, 28 dan 90 hari dari masa perawatan. Kuat tekan beton non-pasir pada umur 28 hari bervariasi antara 1,1 sampai $10 \mathrm{MPa}$, tergantung pada besar proporsi semen berbanding agregat. Campuran menggunakan proporsi semen berbanding agregat $1: 6$ memberikan kekuatan paling tinggi. Kuat tekan dari beton non-pasir lebih rendah dari kuat tekan beton normal, hal ini dikarenakan adanya pertambahan porositas pada beton non-pasir (Abadjieva, T., Sephiri, P., 2000).

\section{Metodologi Penelitian}

\subsection{Lokasi Penelitian}

Penelitian dilakukan di Laboratorium Jurusan Teknik Sipil, Fakultas Teknik, Universitas Malikussaleh.

\subsection{Material}

Agregat kerikil yang digunakan berasal kecamatan Krueng Mane, kabupaten Aceh Utara dengan ukuran maksimum lolos saringan $19 \mathrm{~mm}$. Cangkang kelapa sawit berasal dari pabrik kelapa sawit Lhoksukon, Kabupaten Aceh Utara. Sebelum digunakan cangkang kelapa sawit terlebih dahulu dilakukan pencucian agar minyak dan debu hilang. Selanjutnya cangkang dijemur hingga kering selama 3 hari. Untuk keperluan campuran beton non-pasir, cangkang kelapa sawit yang digunakan adalah berdiameter antara $19-9,5 \mathrm{~mm}$. Sifat fisis lainnya dari agregat diperlihatkan dalam Tabel 1

Semen yang digunakan adalah produksi PT. Semen Andalas, Portland Cement tipe I, dan air yang digunakan berupa air yang dapat diminum. Air ini diperoleh dari air isi ulang produksi depot Aqua Mon Pasee, Lhokseumawe. Untuk semen dan air tidak dilakukan pemeriksaan lagi, karena telah memenuhi persyaratan. 
Tabel 1 Sifat fisis agregat

\begin{tabular}{|c|c|c|c|c|}
\hline \multirow{2}{*}{$\begin{array}{l}\text { No } \\
1\end{array}$} & \multicolumn{2}{|r|}{ Uraian } & Keriki & $\begin{array}{c}\text { Cangkang kelapa } \\
\text { sawit }\end{array}$ \\
\hline & \multicolumn{2}{|c|}{ Berat Volume Padat Agregat $(\mathrm{Kg} / \mathrm{l})$} & 1,656 & 0,584 \\
\hline \multirow{2}{*}{2} & \multirow{2}{*}{$\begin{array}{l}\text { Berat } \\
\text { jenis }\end{array}$} & Kering Jenuh Permukaan & 2,63 & 1,31 \\
\hline & & Kering Tungku/oven & 2,59 & 1,13 \\
\hline 3 & \multicolumn{2}{|r|}{ Absorpsi (\%) } & 1,68 & 15,62 \\
\hline 4 & \multicolumn{2}{|r|}{ kadar air (\%) } & 1,50 & 12,87 \\
\hline
\end{tabular}

\subsection{Benda Uji}

Dalam penelitian ini digunakan benda uji silinder (150 x 300) mm sebanyak 5 buah untuk masing-masing sampel dengan proporsi semen berbanding agregat adalah $1: 3 ; 1: 4 ; 1: 6 ; 1: 8 ; 1: 10$; dan $1: 12$ berdasarkan perbandingan volume. Tabel berikut memperlihatkan proporsi campuran untuk masing-masing benda uji.

Tabel 2 Proporsi campuran beton

\begin{tabular}{|c|c|c|c|c|c|c|}
\hline \multirow{2}{*}{ No } & \multirow{2}{*}{ Benda Uji } & \multirow{2}{*}{$\begin{array}{c}\text { Perbandingan } \\
\text { volume }\end{array}$} & \multirow{2}{*}{$\begin{array}{c}\text { benda } \\
\text { uji (bh) }\end{array}$} & \multicolumn{3}{|c|}{ proporsi per $m^{3}$ beton $(\mathrm{kg})$} \\
\cline { 5 - 7 } & & & & air & semen & $\begin{array}{c}\text { kerikil/ } \\
\text { cangkang sawit }\end{array}$ \\
\hline 1 & BN & $1: 3$ & 5 & 8,779 & 19,509 & 65,844 \\
\hline 2 & Bcs-01 & $1: 3$ & 5 & 8,779 & 19,509 & 23,618 \\
\hline 3 & Bcs-02 & $1: 6$ & 5 & 5,017 & 11,148 & 26,992 \\
\hline 4 & Bcs-03 & $1: 8$ & 5 & 3,902 & 8,671 & 27,992 \\
\hline 5 & Bcs-04 & $1: 10$ & 5 & 3,192 & 7,094 & 28,628 \\
\hline 6 & Bcs-05 & $1: 12$ & 5 & 2,701 & 6,003 & 29,068 \\
\hline
\end{tabular}

Keterangan: $\mathrm{BN}=$ beton non-pasir agregat kerikil, $\mathrm{BCs}=$ beton non-pasir agregat cangkang sawit

\subsection{Pengujian Beton}

\subsubsection{Pemadatan beton segar}

Pemadatan beton non-pasir segar dilakukan dengan alat proktor modifikasi seperti diperlihatkan pada Gambar 2. Pemadatan dilakukan bertahap pada 3 (tiga) lapis dengan tumbukan pada masing-masing lapis sebanyak 25 kali.
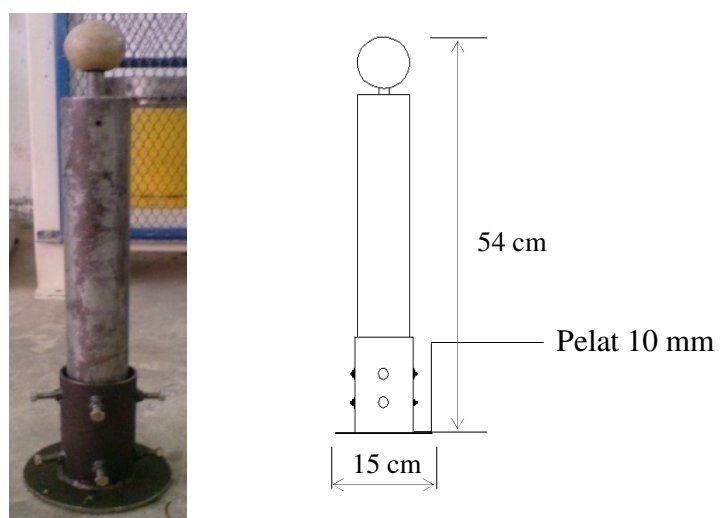

Gambar 2: Alat pemadat beton non-pasir, modifikasi alat proctor 


\subsubsection{Perawatan Benda Uji}

Metode perendaman dalam bak air merupakan perawatan benda uji yang digunakan dalam penelitin ini. Pada umur 21 hari benda uji diberi capping yang terbuat dari mortar semen dengan perbandingan 1 bagian semen dan 1 bagian pasir dengan kebebalan $\pm 10 \mathrm{~mm}$. Pemberian capping dimaksudkan agar permukaan benda uji cukup rata sehingga kekasaran permukaan tidak berpengaruh terhadap pengujian kuat tekan. Sehari setelah pemberian capping, benda uji kembali direndam sampai umur 28 hari.

\subsubsection{Pengukuran kadar air beton}

Pengujian ini dimakudkan untuk mengetahui banyaknya air yang terdapat dalam rongga beton non-pasir setelah perendaman sampai umur beton 21 hari. Tabel 3 memperlihatkan persentase kandungan air dan bobot masing-masing benda uji.

Tabel 3: Berat sampel dan kadar air beton

\begin{tabular}{|c|c|c|c|c|c|c|}
\hline \multirow[t]{2}{*}{ No } & \multirow[t]{2}{*}{ Benda Uji } & \multirow{2}{*}{$\begin{array}{l}\text { Perbandi- } \\
\text { ngan } \\
\text { Volume }\end{array}$} & \multicolumn{2}{|c|}{$\begin{array}{l}\text { Bobot Benda Uji } \\
\text { rata-rata }\left(\mathrm{kg} / \mathrm{m}^{3}\right)\end{array}$} & \multirow{2}{*}{$\begin{array}{l}\text { Penunurunan } \\
\text { bobot terhadap } \\
\text { sample kontrol } \\
\text { (\%) }\end{array}$} & \multirow{2}{*}{$\begin{array}{l}\text { Kadar Air } \\
\text { Beton (\%) }\end{array}$} \\
\hline & & & Basah & Kering & & \\
\hline 1 & BN & $1: 3$ & 1981 & 1876 & 0 & 5,29 \\
\hline 2 & Bcs-01 & $1: 3$ & 1247 & 1173 & 33 & 5,90 \\
\hline 3 & Bcs-02 & $1: 6$ & 877 & 744 & 53 & 15,23 \\
\hline 4 & Bcs-03 & $1: 8$ & 807 & 651 & 57 & 19,36 \\
\hline 5 & Bcs-04 & $1: 10$ & 707 & 511 & 62 & 27,69 \\
\hline 6 & Bcs-05 & $1: 12$ & 673 & 440 & 64 & 34,61 \\
\hline
\end{tabular}

\subsubsection{Pengujian Kuat Tekan}

Seperti halnya pengujian terhadap beton normal, pengujian kuat tekan beton non-pasir pada penelitian ini juga dilakukan pada umur 28 hari. Kuat tekan beton non-pasir yang terbuat dari kerikil (BN) digunakan sebagai sampel kontrol (pembanding). Besarnya kuat tekan beton non-pasir untuk masing-masing benda uji diperlihatkan dalam Gambar 3 dan secara rinci besarnya kuat tekan masingmasing benda uji diperlihatkan dalam Tabel 4.

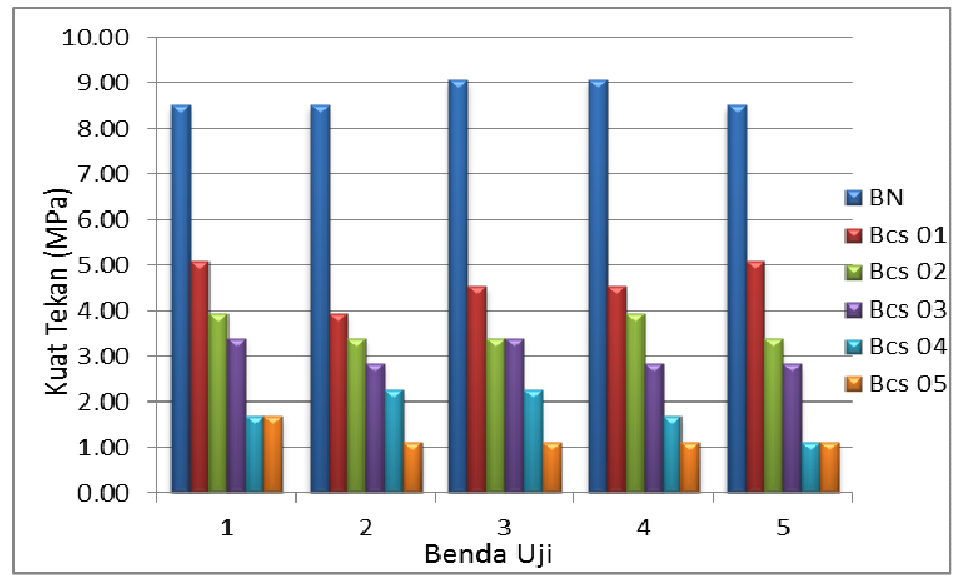

Gambar 3 Kuat tekan masing-masing benda uji 
Tabel 4 Kuat tekan masing-masing benda uji

\begin{tabular}{|c|c|c|c|c|c|c|}
\hline No & Benda Uji & $\begin{array}{l}\text { Perbandi- } \\
\text { ngan } \\
\text { volume }\end{array}$ & $\begin{array}{l}\text { Kuat } \\
\text { Tekan } \\
(\mathrm{MPa})\end{array}$ & $\begin{array}{c}\text { Kuat } \\
\text { Tekan } \\
\text { rata-rata } \\
\text { (MPa) }\end{array}$ & $\begin{array}{c}\text { Standar } \\
\text { Deviasi (s) } \\
\text { (MPa) }\end{array}$ & $\begin{array}{c}\text { Kuat tekan } \\
\text { terhadap } \\
\text { sampel } \\
\text { kontrol } \\
(\%)\end{array}$ \\
\hline \multirow{5}{*}{1} & \multirow{5}{*}{$\begin{array}{c}\text { BN } \\
\text { (kontrol) }\end{array}$} & \multirow{5}{*}{$1: 3$} & 8.49 & \multirow{5}{*}{8.71} & \multirow{5}{*}{0.31} & \multirow{5}{*}{100} \\
\hline & & & 8.49 & & & \\
\hline & & & 9.05 & & & \\
\hline & & & 9.05 & & & \\
\hline & & & 8.49 & & & \\
\hline \multirow{5}{*}{2} & \multirow{5}{*}{ Bcs-01 } & \multirow{5}{*}{$1: 3$} & 5.09 & \multirow{5}{*}{4.64} & \multirow{5}{*}{0.47} & \multirow{5}{*}{53} \\
\hline & & & 3.96 & & & \\
\hline & & & 4.53 & & & \\
\hline & & & 4.53 & & & \\
\hline & & & 5.09 & & & \\
\hline \multirow{5}{*}{3} & \multirow{5}{*}{ Bcs-02 } & \multirow{5}{*}{$1: 6$} & 3.96 & \multirow{5}{*}{3.62} & \multirow{5}{*}{0.31} & \multirow{5}{*}{41.6} \\
\hline & & & 3.40 & & & \\
\hline & & & 3.40 & & & \\
\hline & & & 3.96 & & & \\
\hline & & & 3.40 & & & \\
\hline \multirow{5}{*}{4} & \multirow{5}{*}{ Bcs-03 } & \multirow{5}{*}{$1: 8$} & 3.40 & \multirow{5}{*}{3.06} & \multirow{5}{*}{0.31} & \multirow{5}{*}{35.1} \\
\hline & & & 2.83 & & & \\
\hline & & & 3.40 & & & \\
\hline & & & 2.83 & & & \\
\hline & & & 2.83 & & & \\
\hline \multirow{5}{*}{5} & \multirow{5}{*}{ Bcs-04 } & \multirow{5}{*}{ 1:10 } & 1.70 & \multirow{5}{*}{1.81} & \multirow{5}{*}{0.47} & \multirow{5}{*}{20.8} \\
\hline & & & 2.26 & & & \\
\hline & & & 2.26 & & & \\
\hline & & & 1.70 & & & \\
\hline & & & 1.13 & & & \\
\hline & & & 1.70 & & & \\
\hline & & & 1.13 & & & \\
\hline 6 & Bcs-05 & $1: 12$ & 1.13 & 1.24 & 0.25 & 14.3 \\
\hline & & & 1.13 & & & \\
\hline & & & 1.13 & & & \\
\hline
\end{tabular}

\section{Pembahasan}

Dari Tabel 3 diketahui bahwa seluruh benda uji, baik untuk beton non-pasir agregat kerikil $(\mathrm{BN})$ maupun beton non-pasir agregat cangkang sawit (Bcs) memenuhi kriteria sebagai beton agregat ringan, yaitu masih dalam batasan berat volume $300 \mathrm{~kg} / \mathrm{m}^{3}$ sampai $1900 \mathrm{~kg} / \mathrm{m}^{3}$. Selanjutnya, Tabel 3 juga memperlihatkan bahwa semakin besarnya perbandingan volume cangkang sawit terhadap semen, maka semakin bertambah jumlah air yang dikandung dalam massa beton. Kadar 
air beton non-pasir agregat cangkang sawit (Bcs) berkisar antara 5,9 - 34,61\% dari bobot beton. Besarnya kadar air dalam Bcs merupakan indikator besarnya daya serap air, sehingga Bcs berpotensi sebagai beton yang ramah lingkungan apabila digunakan pada area yang diharapkan dapat menjadi daerah serapan air hujan.

Kuat tekan seluruh benda uji Bcs seperti diperlihatkan dalam Gambar 3 dan Tabel 4 menunjukkan penurunan yang signifikan dibanding BN yaitu berkisar 47\% sampai $86 \%$. Penurunan kuat tekan sangat dipengaruhi oleh perbandingan volume cangkang terhadap semen. Semakin tinggi volume cangkang terhadap semen, maka semikin berkurang massa pasta semen yang dapat menyelimuti cangkang. Hal ini berakibat berkurangnya daya rekat antar cangkang. Penurunan kuat tekan juga disebakan oleh bentuk cangkang sawit yang cekung, sehingg mempengaruhi daya rekat dan interlocking antar cangkang. Sejalan dengan kuat tekan, dari Tabel 3 diketahui bahwa berat volume Bcs juga mengalami penurunan yang drastis dibanding BN, yaitu antara $33-64 \%$.

\section{Kesimpulan}

Dari hasil penelitian yang telah dilakukan dapat diambil beberapa kesimpulan sebagai berikut:

1. Kuat tekan dan berat volume beton non-pasir agregat cangkang kelapa sawit menunjukkan penurunan yang sangat signifikan dibandingkan kuat tekan beton non-pasir agregat kerikil;

2. Makin besar perbandingan volume agregat cangkang kelapa sawit terhadap semen, maka semakin besar rendah kuat tekan dan berat volume beton agregat non-pasir cangkang kelapa sawit;

3. Berlawanan dengan kuat tekan dan berat volume, makin besar perbandingan volume agregat cangkang kelapa sawit terhadap semen, maka semakin besar daya serap air beton agregat non-pasir cangkang kelapa sawit;

4. Beton non-pasir agregat cangkang kelapa sawit memenuhi kriteria sebagai beton ringan non struktural;

5. Sesuai dengan kuat tekan dan daya serap airnya, beton non-pasir agregat cangkang kelapa sawit dapat dimanfaatkan untuk beton non struktural yang ramah lingkungan, semisal pada trotoar pejalan kaki, jalan lintas dalam taman dan paving block penutup pekarangan.

\section{Daftar Kepustakaan}

1. Abadjieva, T., Sephiri, P., 2000, Investigations on Some Properties of NoFine Concrete, Department of Civil Engineering, University of Botswana; Gaborone, Botswana,

2. http://www.irbnet.de/daten/iconda/CIB8837.pdf, diunduh 17 Pebruari 2013.

3. Anonim, 2002, SNI 03-2847-2002 Tata Cara Perhitungan Struktur Beton Untuk Bangunan Gedung, Bandung;

4. Anonim, 2004, What, How and Why: Pervious Concrete, National Ready Mixed Concrete Association, USA;

5. Anonim, 2011, Aceh Utara Dalam Angka 2011, Badan Pusat Statistik Kabupaten Aceh Utara; 
6. Ferguson, B. K., 2005, Porous Pavements, CRC Press, Boca Raton, Florida;

7. Mannan, M. A., Ganapathy, C., 2001, Long-Term Strengths of Concrete with Oil Palm Shell as Coarse Aggregates, Cement and Concrete research, Volume 31, Issue 9, pp. 1319-1321;

8. Mulyono, T., 2004, Teknologi Beton, edisi ke-1, Penerbit Andi, Yoyakarta.

9. Neville, A. M., 1995, Properties of Concrete, 4th Edition, Prentice Hall, Harlow, England;

10. Teo, et. al., 2006, Structural Concrete Using oil Palm Shell (OPS) as Lightweight Aggregates, Turkish Journal Engineering, Environment and Science, Volume 30, pp. 251-257; 